\title{
A experiência do estado de Minas Gerais na efetivação dos direitos do consumidor através de uma política sancionatória consistente
}

\author{
The experience of the state of Minas Gerais on exercise of the rights of consumers \\ through a punitive policy consistent
}

\author{
Wander Henrique de Almeida Costa ${ }^{1}$ \\ Neiva de Fátima Araújo Basílio
}

\begin{abstract}
Resumo
Este trabalho, demonstra que as punições administrativas aplicadas pelos órgãos inseridos nos programas de defesa do consumidor, nem sempre têm suas decisões respeitadas. Sob este aspecto, a sociedade, credora destes direitos, deve se mobilizar para buscar a transformação dos conteúdos programáticos das leis, em direito vivo, histórico e pragmático. Verifica-se pela prática nas relações consumeristas, que os detentores do poder econômico - fornecedores de bens e serviços, em alguns casos, têm resistido à intervenção de órgãos de defesa do consumidor, levando as soluções administrativas propostas para os Tribunais Judiciais e, através de verdadeiras batalhas judiciais, retardam e desestimulam o cumprimento de direitos consumeristas, como é demonstrado em algumas experiências referidas neste trabalho. Sob este aspecto, não se constata a existência de uma efetiva justiça consumerista uma vez que esta deve extrair sua autoridade moral de razões públicas. Com fulcro neste paradigma de justiça, espera-se, que a sociedade através de seus representantes, produza dispositivos coativos mais eficazes, afastando, por temor de mal maior, as pendengas sem importância do Poder Judiciário, que quase sempre minimiza a efetividade das leis de defesa do consumidor, perpetuando no tempo a prática injusta nas relações consumeristas decorrentes do abuso do poder econômico.
\end{abstract}

Palavras-chave: Constituição. Direito Admnistrativo. Defesa do consumidor.

\begin{abstract}
This work demonstrates that the penalties imposed by administrative organs included in programs of consumer protection does not always have your decisions respected. In this respect, society, these creditor rights, should be mobilized to seek the transformation of the syllabus of the laws, in law live, historical and pragmatic. There is the practice in relations consumeristas, that holders of economic power suppliers of goods and services, in some cases, have resisted the intervention of consumer protection agencies, leading administrative solutions proposed for the Courts and through true legal battles, delays and discourage compliance
\end{abstract}

\footnotetext{
Pesquisador da Fundação Brasileira de Direito Econômico, Mestrando em Direito Público pela PUC/MG.

Graduada em Direito.
} 
consumeristas rights, as demonstrated in some experiments referred to in this work. In this regard, it notes the existence of an effective justice consumerist since it must draw its moral authority of public reasons. With this core paradigm of justice, it is expected that the society through their representatives, produce more effective coercive devices away, for fear of greater evil, the pendengas unimportant the judiciary, which often reduces the effectiveness of laws consumer protection, in time perpetuating the unjust practice consumeristas relations arising from the abuse of economic power.

Keywords: Constitution. Administrative law. Consumer protection.

\section{Introdução}

As normas jurídicas são constituídas por duas partes: uma denominada proposição, que determina uma modalidade de conduta; a outra é denominada sanção, que motiva o cidadão a não descumpri-la, sendo, portanto, imputada a sanção ao agente infrator da proposição, para desestimulá-lo da prática considerada danosa para a sociedade.

A promulgação do Código de Defesa do Consumidor (Lei 8.078, de 1990), marcou o início de uma nova fase das relações consumeristas no Brasil. Com 21 (vinte e um) anos de vigência, apresenta-se um bom momento para verificar se a existência desta lei, que se pauta pela defesa da sociedade nas relações de consumo com os donos do poder econômico, tem validade moral e material.

$\mathrm{Na}$ prática, significa dizer que, os modelos adequados de conduta para o relacionamento de consumo, entre fornecedor e consumidor, estão sendo seguidos de maneira em que fique estabelecida uma relação de justiça contratual, significa "não lesar ninguém", conforme Justiniano ${ }^{3}$.

Demonstra-se, através da experiência nas relações consumeristas, inclusive algumas experiências de exemplos fáticos, que os detentores do poder econômico - fornecedores de bens e serviços em alguns casos têm resistido em aceitar a intervenção de órgãos de defesa do consumidor, levando as reclamações e soluções administrativas propostas para os Tribunais Judiciais; e através de verdadeiras batalhas judiciais, retardam e desestimulam o cumprimento de direitos consumeristas, demonstrando, através do descumprimento das

\footnotetext{
3 “Corpus iuris civilis, coleção de direito civil (não-canônico), organizada pelo Imperador Romano Justiniano resume todas as exigências do direito em três princípios[...]:viver honestamente, não lesar ninguém e dar a cada um o que é seu.". .(HOFFE, 2003, p.57)
} 
normas consumeristas, o desrespeito a princípios fundamentais e sociais importantes, como os da dignidade e da justiça contratual.

Para coibir abusos do poder econômico a partir das decisões administrativas, surgem as punições pelo PROCON aos "donos do capital” (FAÓRO, 1958). Estes se socorrem do Poder Judiciário, para reduzir as sanções ou mesmo procrastiná-las através de infindáveis e serosos recursos processuais, reduzindo o grau de eficácia do Código de Defesa do Consumidor.

O principal objetivo do estudo, portanto, é contribuir para o melhor entendimento a respeito da efetividade do Código de Defesa do Consumidor nas relações consumeristas. Não resta dúvida de que existe um desequilíbrio nas relações de consumo; o consumidor é hipossuficiente, enquanto que o fornecedor de bens e serviços é quem dita as regras em que se dará o relacionamento consumerista. Por isso, necessário se faz, um instrumento de defesa do consumidor que garanta o equilíbrio nas relações de consumo, especialmente diante do contexto da globalização com negócios sendo feitos numa grande velocidade e não raramente de maneira virtual.

Segundo Habermas (2002), "É contra-intuitivo que uma concepção pública de justiça deva extrair sua autoridade moral de razões não públicas." Nesse paradigma sociológico, reafirma-se que, uma hermenêutica positivista, que não acompanha o processo histórico dialético que constrói os contornos do mundo presente, afasta-se dos ideais de uma sociedade complexa, plural e que se pretende permeada de igualdade.

A pesquisa que deu origem a este texto partiu do pressuposto que, sendo o Direito do Consumidor oriundo do Estado, eis que se apresenta como o administrador deste modelo de conduta. Faz-se necessário lançar um olhar para os aspectos mais importantes do Direito e do Processo Administrativos, para se alcançar os resultados desejados; tanto quanto para alguns princípios norteadores do ordenamento jurídico e daqueles que fundamentam e norteiam a defesa do consumidor no Código de Defesa do Consumidor.

Dentre estes se pode ressaltar o princípio da justiça contratual, que trata da relação de paridade estabelecido nas relações comutativas, e que explicita que nenhuma das partes dê mais ou menos do que recebeu. Esse princípio se desdobra em "princípio da proteção ao hipossuficiente" e em "princípio da proteção genérica do devedor", In dúbio pro debitore, 
porque, afinal, o consumidor é quem suporta o ônus da prestação pecuniária da aquisição de bens ou da prestação de serviços.

O princípio da dignidade da pessoa humana é igualmente um valor a ser realizado pelo ordenamento jurídico, consagrado no Estado Democrático de Direito Brasileiro, com base no qual se fundamentam todas as normas jurídicas constitucionais e infraconstitucionais, bem como as interpretações de todas as situações jurídicas, inclusive os contratos.

Outro ponto importante de reflexão é saber como o Programa de Proteção e Defesa do Consumidor atua face ao processo administrativo, as decisões que toma em face dos mesmos e como aplica as punições administrativas, oriundas de sua atuação frente aos direitos do consumidor.

No caso do Código de Defesa do Consumidor, em conjunto os modelos de conduta e as sanções administrativas inseridas no texto, foram criadas, para dar efetividade à lei e entidades especializadas públicas e privadas para fiscalizar e aplicar punições administrativas com vistas a coibir o abuso do poder econômico.

Em Minas Gerais, as instituições públicas que tratam das relações consumeristas, são o PROCON-MG (Programa Estadual de Proteção e Defesa do Consumidor), o Ministério Público e o Poder Judiciário, através dos Juizados Especiais de Defesa do Consumidor. Nos municípios, especialmente nos mais populosos foi criadoi também PROCON Municipal.

Ocorre que estes órgãos públicos nem sempre estão sincronizados, e isso faz com que se perca uma importante parcela da efetividade que a sociedade deseja e o legislador pretendeu imprimir, e que se faz bastante necessária ao Código de Defesa do Consumidor. Não são raras as vezes que o PROCON, o Ministério Público e o Poder Judiciário se desentendem, minimizando com isso as punições administrativas impostas pelo PROCON em sua atividade de salvaguardar o consumidor.

Para demonstrar isso, serão revistos dois processos administrativos que tramitaram junto ao PROCON e tiveram uma significativa repercussão midiática na esfera do consumidor; o caso Toyota Corolla e o caso relativo aos Pontos extras de TV a cabo.

Os resultados dos casos da Toyota Corolla e do Ponto Extra de TV a Cabo demonstraram que, as punições administrativas quase sempre são eficazes. Quase sempre, por certo existem decisões administrativas tomadas pelo PROCON que são minimizadas pela 
interferência indireta do Poder Judiciário, diminuindo com isso a eficácia da lei do consumidor. Para produzir resultados mais consistentes seria necessário que a sociedade produzisse uma legislação sancionatória mais danosa para o infrator das leis consumeristas, de modo que, paulatinamente, se conseguisse aumentar o grau de efetividade e de eficácia das leis de proteção ao consumidor.

\section{Aspectos conceituais do Direito Administrativo, do Direito Econômico e do Direito do Consumidor}

Em relação ao Processo Administrativo, pode-se dizer que existem estudos apontando que o Direito Constitucional determina a fisionomia do Direito Administrativo de cada país, seus contornos básicos, seus vetores e perspectivas. Dessa forma, a Constituição regulamenta todos os institutos interessantes ao Direito Administrativo (MELLO, 2006).

O Direito Administrativo pode ser entendido como o conjunto de princípios e de regras que regem a atividade que o Estado desenvolve, através de atos concretos e executórios, para a consecução direta, ininterrupta e imediata dos interesses públicos.

Segundo Di Pietro,

O Direito Administrativo é o ramo do Direito Público que tem por objeto os órgãos, agentes e pessoas jurídicas administrativas que integram a Administração Pública, a atividade jurídica não contenciosa que exerce e os bens de que se utiliza para a consecução de seus fins, de natureza pública. (DI PIETRO, 2007, p.81)

Para Pietro (2002), apesar da constatação de o Direito Administrativo não ser recente, percebe-se que ele vem mudando de feição. O objetivo principal dessa mudança é melhorar o funcionamento da Administração Pública agregando o princípio da eficiência, ora consignado na Constituição Federal (CF/37).

Nesse sentido acentua Pietro:

O princípio da eficiência apresenta, na realidade, dois aspectos: pode ser considerado em relação ao modo de atuação do agente público, do qual se espera o melhor desempenho possível de suas atribuições, para lograr os melhores resultados; e em relação ao modo de organizar, estruturar, disciplinar a Administração Pública, também com o mesmo objetivo de alcançar os melhores resultados na prestação do serviço público (DI PIETRO, 2007, p.83). 
O princípio da eficiência se vincula também ao princípio da economicidade uma vez que a organização, o planejamento e o aumento da qualidade da prestação dos serviços administrativos são causas de diminuição dos gastos públicos.

O direito administrativo se vincula ainda ao direito econômico à medida que é inevitável a interlocução da Administração Pública com as instituições econômicas de direito público e privado. Na Constituição Brasileira se vislumbra que "a ordem econômica, fundada na valorização do trabalho humano e na livre iniciativa, tem por fim assegurar a todos existência digna, conforme os ditames da justiça social [...]” (BRASIL, 1988).

Verifica-se então que as relações econômicas, dentre as quais as relações consumeristas, devem se dar num ambiente impregnado de dignidade e de justiça social. Para tanto, se torna necessário estabelecer normas de conduta, de modo a assegurar os princípios constitucionais da ordem econômica.

De acordo com Mello:

[...] sem prejuízo de repetir que a Constituição estabeleceu uma grande visão: de um lado, atividades que são da alçada dos particulares - as econômicas; e, de outro, atividades que são da alçada do Estado, logo, implicitamente qualificadas como juridicamente não econômicas - os serviços públicos. De par com elas, contemplou, ainda, atividades que podem ser da alçada de uns ou de outro (MELLO, 2006, p.756).

Entende-se que o contexto das atividades econômicas e das atividades não econômicas está bem discriminado pela Constituição, o que favorece uma melhor implantação da ordem econômica. Nesse contexto, vislumbra-se o Direito Econômico. Segundo Clark (1994), o Direito Econômico deve assegurar aos consumidores suas garantias constitucionais, regulamentando as políticas econômicas dos precursores das atividades econômicas, com o intuito de harmonizar interesses individuais e coletivos, de realizar a justiça social e de proteger os economicamente fracos.

Com base no Direito Econômico, nota-se que a ordem econômica não é estabelecida fora do Estado, ou seja, há uma regulamentação regida pelo Estado, que visa preservar tal ordem.

Segundo Mello, 
considerando-se panoramicamente a interferência do Estado na ordem econômica, percebe-se que esta pode ocorrer de três modos; a saber: (a) ora dar-se-á através de seu 'poder de polícia', isto é, mediante leis e atos administrativos expedidos para executá-las, como 'agente normativo e regulador da atividade econômica' - o caso no qual exercerá funções de 'fiscalização' e em que o 'planejamento' é 'determinante para o setor público', tudo conforme prevê o art. 174; (b) ora ele próprio, em casos excepcionais, como foi dito, atuará empresarialmente, mediante pessoas que cria com tal objetivo; e (c) ora o fará mediante incentivos à iniciativa privada (também supostos no art. 174), estimulando-a com favores fiscais ou financiamentos, até mesmo a fundo perdido (MELLO, 2006, p.757).

Portanto, o papel do Estado na ordem econômica vai além de apenas normalizar, regulamentar e fiscalizar a atividade econômica, ou seja, atua de acordo com as necessidades sociais, sejam estas referentes ao setor público ou à iniciativa privada.

Chama-se a atenção para outro dado importante: o Direito do Consumidor é por sua vez, um ramo do Direito Econômico destinado a proteger penalmente as relações de consumo.

Magatão (2010) explicita que com a promulgação da Constituição de 1988, a proteção do consumidor veio à tona com maior impacto. A partir desse momento, pode-se dizer que foi criado o status "consumidor" e que tem origem a sua codificação tutelar: a defesa do consumidor foi reconhecida como direito fundamental (art. 5으, XXXII) e princípio da ordem econômica (art. 170, V).

Para Filomeno,

[...] o chamado Direito do Consumidor (em verdade um somatório de interesses) vale muito mais pelos instrumentos colocados à sua disposição do que propriamente por um corpo sistematizado de normas do mais amplo espectro, sua efetiva defesa ou ainda sua proteção. Entendemos que tal se dá nos âmbitos administrativo, civil e penal, atribuindo-se a todos os órgãos, entidades públicas ou privadas, empresas etc., determinadas atividades, ou até abstenções de atos com vistas em atingir-se tal escopo, no sentido mais amplo possível (FILOMENO, 2006, p.136).

Assim, Filomeno (2005) aponta que o Direito do Consumidor ressalta mais a implementação dos recursos ligados diretamente à sua manutenção do que a um conjunto normativo.

Faz-se relevante também conceituar de forma mais precisa o que se denomina "poder de polícia", caracterizado por Mello (2006), como a atividade estatal de condicionar a liberdade e a propriedade, ajustando-as aos interesses coletivos. A expressão, tomada nesse 
sentido amplo, abrange tanto atos do Legislativo quanto do Executivo. Refere-se, pois, ao complexo de medidas do Estado que delineia a esfera juridicamente tutelada da liberdade e da propriedade do cidadão.

Por isso, nos Estados Unidos, a voz police power reporta-se sobretudo às normas legislativas, através das quais o Estado regula os direitos privados, constitucionalmente atribuídos aos cidadãos, em proveito dos interesses coletivos, como bem anota Caio Tácito (Mello 2006, p. 780).

Segundo o autor, a expressão "poder de polícia" ainda pode ser tomada em sentido mais restrito, relacionando-se unicamente com as intervenções, quer gerais e abstratas, como os regulamentos, quer concretas e específicas (tais como as autorizações, as licenças, as injunções) do Poder Executivo, destinadas a alcançar o mesmo fim de prevenir e obstar ao desenvolvimento de atividades particulares, contrastantes com os interesses sociais. Esta acepção mais limitada responde à noção de polícia administrativa.

Portanto, é importante reconhecer que o ordenamento jurídico pátrio acentua e conceitua o Direito Administrativo como a forma ordenada que disciplina as relações estatais, e neste contexto é responsável pela implementação e condução das políticas econômicas, assentadas numa ordem econômica fundada na valorização do trabalho humano, na livre iniciativa e nos princípios da dignidade e da justiça social.

\subsection{Aspectos históricos do processo administrativo}

No século XVIII, ocorreu o fenômeno que provocou o aparecimento da empresa e da moderna administração, e se estendeu ao longo do século XIX, chegando ao limiar do século XX. Esse fenômeno, que trouxe rápidas e profundas mudanças econômicas, sociais e políticas, chamou-se Revolução Industrial. Nesse sentido acentua Souza:

\footnotetext{
Antes da era industrial, o produtor-fabricante era simplesmente uma ou algumas pessoas que se juntavam para confeccionar peças e depois trocar os objetos (bartering) ${ }^{4}$. Com o crescimento da população e o movimento do campo para as cidades, formam-se grupos maiores, a produção aumentou e a responsabilidade se concentrou no fabricante, que passou a responder por todo o grupo (SOUZA, 1996, p.48).
}

\footnotetext{
4 Termo em inglês que se refere à troca de mercadoria.
} 
Conforme explicita Gomes (2005), ao final desse período, o mundo já não era mais o mesmo, e a Administração Moderna surgiu em resposta à necessidade provocada pela Revolução Industrial de imprimir maior eficiência às empresas, que cresciam acelerada e desordenadamente.

Segundo Clark (1994, p.16), com o desenvolvimento do Capitalismo que se multiplicou no decorrer dos anos devido aos avanços tecnológicos, à expansão dos mercados consumidores, à divisão de classes e categorias econômicas, o sistema econômico social dos países capitalistas entra em crises cíclicas, o que por sua vez exige uma nova postura perante a administração socioeconômica dos países.

Clark (1994) explicita ainda que neste contexto o "Estado, então, é chamado para limitar a concorrência; evitar o abuso do poder econômico, reprimir os monopólios, intervir e dirigir a economia, proteger os economicamente fracos e fazer a justiça distributiva ${ }^{5 \prime \prime}$.

Como se pode observar, o Processo Administrativo vem sendo construído ao longo dos anos através de diferentes momentos históricos. Assim, necessário se faz abordar o Processo Administrativo no Brasil contemporâneo.

\title{
2.2 O processo administrativo no Brasil
}

No Brasil, o Direito Administrativo tem suas origens fincadas no período colonial. Apesar de não haver traços de autonomia desse ramo do Direito Administrativo, nessa época existia uma normalização das relações de governo.

Conforme ressalta Virgínia Maria Almoêdo de Assis, em texto apresentado no seminário O Mundo que o Português Criou:

\begin{abstract}
A formação de um aparelhamento administrativo no Brasil pela Coroa Portuguesa tem início com o estabelecimento das Donatárias em 1532, momento em que a política lusa norteava-se no sentido de transformar a terra conquistada em colônia de exploração sob o esteio jurídico do Tratado de Tordesilhas e de várias Bulas Pontifícias (ASSIS, 2000, p.2).
\end{abstract}

Segundo Di Pietro (2002), não existia um Direito Administrativo como um processo autônomo tal como existe hoje, mas existiam normas que regiam as relações do Monarca

\footnotetext{
5 Justiça distributiva refere-se à distribuição justa, equitativa e apropriada na sociedade determinada para justificar normas que estruturam os termos da cooperação social.
} 
com seus delegados, com a Igreja e com os colonos. Não sendo a estrutura administrativa de todo contemporânea, pode-se considerar que o exercício de administrar é uma condição essencial da existência coletiva.

No Direito Administrativo, há pilares que buscam atender ao interesse público. Com relação ao Processo Administrativo não poderia ser diferente; a utilidade pública ligada ao interesse do Estado faz parte da finalidade do Processo Administrativo.

Convém ressaltar que a trajetória histórica, referente ao Processo Administrativo no Brasil, contribuiu positivamente para a sua evolução. Conforme aponta Faria (2007), apesar de ser ainda novo, o Direito Administrativo Brasileiro já pode ser comparado ao Direito Administrativo de países do Primeiro Mundo:

O Direito Administrativo brasileiro encontra-se no mesmo nível do Direito Administrativo dos países de Primeiro Mundo, no que tange a normatização, à teorização, à doutrina e ao campo de realização. Os administradores brasileiros vêm desenvolvendo pesquisas com seriedade e desprendimento na busca do Direito Administrativo adequado e compatível com as necessidades da Administração Pública e aos interesses coletivos (FARIA, 2007, p. 26).

É importante mencionar que essa evolução, que acompanha o desenvolvimento do Estado de Direito, só foi possível através de todo o processo histórico, que contribuiu para o desenvolvimento do Processo Administrativo Brasileiro. A Constituição da República, ao dispor sobre a Administração Pública e fixar os parâmetros de sua atuação, indica os princípios que deverão nortear o Processo Administrativo.

De forma explícita, a Constituição estabelece em seu art. 5ㅇ, LX: “Ninguém será privado da liberdade ou de seus bens sem o devido processo legal." Como visto anteriormente, o Processo Administrativo tem passado por mudanças com vistas a atender às demandas sociais contemporâneas.

\section{3 - O PROCON e o processo administrativo}

Considerando os órgãos de defesa do consumidor, observa-se que estes estão presentes nos âmbitos Federal, Estadual e Municipal. Filomeno (2005) acentua que:

O que se observa até então, junto aos diversos órgãos precípuos de proteção e defesa do consumidor, a começar pelo federal (Departamento Nacional de 
Proteção e Defesa do Consumidor), passando pelo estadual (PROCON Coordenadoria de Proteção de Defesa do Consumidor) e chegando até o municipal (Sistema Municipal de Defesa do Consumidor do Município da Capital - Decreto $\mathrm{n}^{\circ}$ 29.590, de 11.3.91), era uma verdadeira ânsia de poder de polícia administrativa que, além de não lhes ser próprio, causaria certamente enormes transtornos em sua organização (FILOMENO, 2005, p.142).

A pesquisa identificou as três esferas em que os órgãos de proteção e defesa do consumidor estão ambientados, no entanto, será abordado com mais detalhes o PROCON Proteção e Defesa do Consumidor no âmbito Estadual, especificamente, no Estado de Minas Gerais.

Filomeno (2005) explica que, com efeito, a Lei Estadual $\mathrm{n}^{\circ} 1.903$, de 29 de dezembro de 1978, já criara o Sistema Estadual de Proteção ao Consumidor, composto em última análise pelo PROCON como órgão executivo, e o Conselho Estadual de Proteção ao Consumidor, como órgão colegiado deliberativo. E, recente a lei estadual transforma o PROCON em fundação de direito público, o que poderá emprestar-lhe maior agilidade no tocante à atuação em defesa do consumidor.

Ainda segundo Filomeno (2005), certo é que além da criação desse sistema estadual (aliás, pioneiro no país), o art. $3^{\circ}$ do referido diploma legal define, de forma clara suas atribuições às quais não se encontra, em lugar algum, eventual atividade de fiscalização ou, em última análise, de polícia administrativa.

Convém ressaltar que o PROCON-MG, Programa Estadual de Proteção e Defesa do Consumidor de Minas Gerais, surge sob a influência das donas de casa no momento em que essas começam a se unir de forma organizada, já na década de 1970, culminando em um dos mais representativos movimentos sociais hodiernos, a Associação das Donas de Casa. 0 trabalho inicial dessas senhoras era o de comparar, realizar pesquisas no mercado e exigir um atendimento respeitoso, ocasionando a criação do primeiro PROCON, autorizado pela Lei 1.903/78 e concretizado no ano seguinte. Dentre as entidades civis surge também o Instituto de Defesa do Consumidor (IDEC) e outras iniciativas que fortalecem o desenvolvimento da defesa do consumidor no Brasil.

De acordo com o Projeto de Lei Complementar no 58/2010, o PROCON-MG está presente em todo o estado de Minas Gerais, através das Promotorias de Justiça de Defesa do Consumidor. Apesar de ser conhecido como um dos mais eficientes órgãos de defesa do 
consumidor, o PROCON-MG tem novos desafios impostos pelo mercado de consumo, tornando necessário o aperfeiçoamento e aprimoramento de sua atuação.

Em face de o Ministério Público apresentar um papel preponderante quanto à proteção e defesa do consumidor, Filomeno (2005) destaca a importância dessa atuação frente aos direitos do consumidor:

A primeira menção ao Ministério Público no Código do Consumidor verifica-se no inc. Il do seu art. 5, como já referido, quando coloca a mencionada instituição como um dos instrumentos de execução da Polícia Nacional das Relações de Consumo. Referido dispositivo dispensa maiores explicações, diante do que foi exposto em itens anteriores, convindo sempre ressaltar que, sobretudo em se tratando de efetivos instrumentos práticos de defesa ou proteção do consumidor, mormente no âmbito individual, efetivamente é a Promotoria de Justiça um dos órgãos de que normalmente se socorre o consumidor quando se vê diante de um impasse oriundo de determinada relação de consumo (FILOMENO, 2005, p. 125).

Portanto, faz-se necessário esclarecer o papel do Ministério Público consoante a Constituição Federal. O art. 127 da Constituição Federal Brasileira aponta que o Ministério Público é uma instituição permanente, que deve zelar pela defesa da ordem jurídica, dos interesses sociais e individuais indisponíveis.

A “Lei Orgânica Federal do Ministério Público" (Lei Federal n 8.625 de 12 de fevereiro de 1993) estabelece, em seu art. 25, que:

além das funções previstas nas Constituições Federal e Estadual, na Lei Orgânica e outras leis, incumbe, ainda, ao Ministério Público: [...] promover o inquérito civil e a ação civil Pública, na forma da lei: a) para a proteção, prevenção e reparação dos danos causados ao meio ambiente, ao consumidor, aos bens e direitos de valor artístico, estético, histórico, turístico e paisagístico, e a outros interesses difusos, coletivos e individuais e homogêneos (MELLO, 2006, p 116).

De acordo com Filomeno:

E a 'Lei Orgânica do Ministério Público do Estado de São Paulo' (Lei Complementar $n^{\circ} 304$, de 28.12.82), em seu art. 32, que cuidava das atribuições do ProcuradorGeral de Justiça, já previra, no inciso I, $n^{\circ} 34$, alínea b, que era sua atribuição administrativa 'designar', em cada comarca do Estado, um membro do Ministério Público, a quem se incumbirá, no exercício de curadoria especializada, a proteção e defesa, no plano administrativo, dos direitos do consumidor (FILOMENO, 2006, p.115). 
Desse modo, com relação às atribuições de Promotoria do Consumidor, observa-se que, no plano administrativo, o Ministério Público tem um papel fundamental para a legitimação dos direitos do consumidor.

Para a melhor compreensão do papel do PROCON, faz-se necessário compreender o significado do termo "consumidor". Clark (1994) mostra que os juristas modernos ainda apresentam formas diferentes de conceituar "consumidor", como é o caso de Antônio Benjamim e José Geraldo Filomeno:

Todo aquele que, para seu uso pessoal ou de família adquire ou utiliza produtos, serviços ou qualquer outro bem colocados à sua disposição por comerciantes ou por qualquer pessoa natural ou jurídica no curso de sua atividade ou conhecimento profissional (BENJAMIN; FILOMENO apud CLARK , 1987, p.194).

A Confederação Nacional do Ministério Público conceitua como consumidor:

[...] adquirente ou usuário eu utiliza, para fins não profissionais, produtos ou serviços colocados à sua disposição tanto por comerciantes, como por particulares que exercitem a produção ou distribuição de bens de consumo, ou até mesmo pelo Estado (BENJAMIN; FILOMENO, 1985, p.73).

É interessante notar que, apesar de não existir uma uniformidade na conceituação de consumidor, essas se complementam, ao se considerar os vários doutrinadores e os juristas que tratam desse assunto.

Visto que este estudo analisa a eficácia das punições administrativas na esfera do consumidor, os conceitos de Clark (1994) e do Código de Defesa do Consumidor são fundamentais. Clark (1994) mostra o consumidor como uma "pessoa física que adquire, usa ou se beneficia de bens e serviços para consumo final, independente da manifestação de vontade e sem intuito comercial ou produtivo". O Código de Defesa do Consumidor (CDC) caracteriza como consumidor "toda pessoa física ou jurídica que adquire ou utiliza produto ou serviço como destinatário final”.

Nesse contexto, o PROCON atua na defesa dos direitos dos consumidores. Há de se observar a sequência de procedimentos necessários para um acordo ou que culmine em uma punição administrativa. Filomeno (2005) afirma que o PROCON, Centro de Estudos e Apoio ao Desenvolvimento de Comunidades (CEDECON) ou Serviço de Defesa do Consumidor (SEDECON) têm papel relevante na tentativa de solução conciliatória dos 
conflitos individuais surgidos das relações de consumo, uma vez que atua na defesa dos interesses do consumidor, cumprindo a triagem das reclamações efetivadas.

Ainda segundo Filomeno (2005), a partir das queixas pessoais que são feitas, seja através do comparecimento do reclamante aos postos de atendimento, ou por carta, representações, petições ou mesmo telefonemas, de qualquer forma, preenche-se o chamado Controle de Atendimento (CA) ou ficha de atendimento.

Desse modo, são anotados os dados dos interessados (reclamante e reclamado), o teor da reclamação e seu andamento, finalizando com a resolução ou parecer técnico. Um passo importante desse controle de atendimento além do parecer técnico ou resolução, é sua classificação da matéria, exatamente porque se canaliza cada reclamação ao setor especializado, e pode mais facilmente "trabalhá-la", conforme jargão empregado no âmbito do PROCON de São Paulo, formando ainda uma espécie de "procedimento padrão" de encaminhamento, ou ainda, certa "jurisprudência na tratativa de cada reclamação".

De acordo com Filomeno (2005), as partes recebem "notificações" e "convites" na tentativa de conciliação; isto se a carta modelo "M 1-A" não for suficiente para resolver a pendência. Essa (carta) consiste na entrega, pelo próprio reclamante ao reclamado, de um resumo da reclamação e seu enquadramento legal, sugerindo-se desde logo a solução entre eles próprios.

O autor aponta que, havendo o acordo - o que ocorre muitas vezes -, é lavrado um termo apropriado, firmado por duas testemunhas; o que Ihe confere o valor de título executivo extrajudicial nos termos do que preconiza o inciso III do art. 585 do Código de Processo Civil.

Acentua Filomeno, outros procedimentos adotados pelo PROCON:

Orientação ao consumidor, em caso de não obtenção da desejada conciliação, ou então do descumprimento do que ficara acordado; ou então, na hipótese de notícia de um ilícito penal, aliado ao aspecto civil no sentido de constituir advogado, para propor a ação judicial competente. Ainda nesse aspecto, convém salientar que nem sempre o consumidor terá condições de arcar com as custas de um processo judicial, razão pela qual deverá ser encaminhado à Procuradoria de Assistência Judiciária do Estado, ou então a departamentos de assistência judiciária das faculdades de direito, sindicatos e outras entidades, designação ou provisão de patronos dativos. No primeiro caso, enquanto não existe a defensoria pública, temse adotado a solução do estabelecimento de convênios entre a Secretaria de Justiça e a Ordem dos Advogados do Brasil, ante a insuficiência dos quadros da mencionada procuradoria de assistência judiciária (FILOMENO, 2005, p.164). 
No caso de ausência de acordo entre as partes, o PROCON interage com outros órgãos para efetivar a defesa do consumidor, como se vê na denúncia ao Ministério Público de empresas que descumprem a legislação consumerista e que lesam a coletividade de consumidores.

Desse modo, Carvalho (2005) menciona que a Promotoria Pública recebe não só reclamações pessoais, mas todos os casos considerados como insolúveis junto ao PROCON, relativos ao direito coletivo. Nesse caso, o MP, aceitando a denúncia, faz a autuação e surge o procedimento de inquérito civil público na Promotoria.

\subsection{O processo administrativo e as punições administrativas do PROCON-MG}

Em 1982, ocorreu a inauguração do PROCON Estadual em Minas Gerais, período em que os direitos consumeristas ainda eram pouco difundidos e muito menos aplicados. Os comerciantes e prestadores de serviços se impunham e não deixavam nenhum espaço para o avanço dos direitos consumeristas.

Aos poucos e durante os anos que se seguiram, o Sistema de PROCON foi encorpando, chegando ao ponto atual de o Estado de Minas Gerais contar com aproximadamente 100 (cem) PROCON, uma Delegacia Especializada do Consumidor e um Juizado Especial das Relações de Consumo, melhorando o atendimento e implementando de forma mais aguda os direitos consumeristas no cotidiano jurídico mineiro.

Na primeira metade dos anos 90 (noventa), casos graves e repetitivos lesivos aos consumidores deram origem, através do PROCON, às ações coletivas judiciais elaboradas para enfrentar os problemas mencionados.

Essas ações civis públicas promovidas pelo Ministério Público nos anos de 1993 e 1994 tiveram grande repercussão midiática, chamando a atenção de setores econômicos importantes no sentido de prestarem um serviço de melhor qualidade. Essa reviravolta na relação fornecedor/consumidor serviu para estimular órgãos não governamentais (como, por exemplo, o Movimento das Donas de Casa), a proporem suas próprias ações civis públicas, voltadas principalmente para temas relacionados com direitos sociais, educação e saúde.

Como uma garantia constitucional dada a todos os indivíduos da nação, o direito ao consumo resume-se em estabelecer uma justiça social e uma real democracia, ou seja, 
permitir a toda a sociedade consumir os bens e serviços necessários à sua digna existência (CLARK, 1994).

Os conflitos que surgem oriundos das relações de consumo devem de alguma forma ser solucionados, visando aos interesses do consumidor, pois este é o sujeito tutelado pelo Código de Defesa. Filomeno (2005) explica que o PROCON tem um papel de mediador, no que diz respeito aos conflitos que surgem das relações de consumo:

\begin{abstract}
Abstraindo-se a possibilidade de fiscalização de estabelecimentos comerciais em matéria de comercialização e outros aspectos relativos à policia administrativa (vide Decreto $\mathrm{n}^{\circ}$ 2.181/97), ou então atribuições outrora fixadas pela Lei Delegada $\mathrm{n}^{\circ} 4$, de 1962, notadamente no que dispõe o art. 10, diríamos que os PROCONs, Cedecons ou Sedecons, na defesa dos interesses, cumprindo-lhes a triagem das reclamações efetivadas, sobretudo no encaminhamento aos órgãos competentes, quando o caso (i.e., dentro do já tratado 'âmbito administrativo' da defesa ou proteção ao Consumidor - vide Capítulo 5, item 5.2 para a tomada das providências cabíveis), ou então orientação do consumidor e sobretudo têm papel relevante na tentativa de solução conciliatória dos conflitos individuais surgidos das relações de consumo (FILOMENO, 2005, p. 406).
\end{abstract}

Portanto, a partir do momento em que o consumidor que se vê com a aquisição de um produto defeituoso, ou com a prestação de um serviço malfeito e o problema não é solucionado diretamente com o fornecedor, o PROCON atua como facilitador do acesso à justiça através das audiências de conciliação e conta com o apoio do Ministério Público, para auxiliá-lo em conflitos de difícil solução.

Para Filomeno (2005), falar em defesa do consumidor no âmbito civil implica referirse diretamente à satisfação do consumidor em relação a prejuízos sofridos em decorrência de dada relação de consumo, ai mesmo com relação ao próprio adimplemento das obrigações assumidas pelo produtor de bens e serviços ou ainda na prevenção de prejuízos.

Segundo Filomeno 2005, faz-se necessária a conceituação de Responsabilidade Civil para a compreensão das punições aplicadas pelo Órgão de Defesa do Consumidor. A Responsabilidade Civil pode ser entendida como a circunstância de alguém ser compelido a ressarcir algum prejuízo causado a outrem pela prática de um ato ilícito, quer por dolo, quer por culpa.

No que se refere ao Processo Administrativo, Filomeno (2005) ressalta:

Quanto ao Processo Administrativo, o Decreto 2.181/97 dedica-lhe o Capitulo V, iniciado pela Seção I, que traça disposições gerais, no que tange ao início de todos 
os procedimentos, a saber: mediante ato, por escrito, da autoridade competente, lavratura de auto de infração, ou reclamação de qualquer interessado. Diz ainda o $\S 1^{\circ}$ do seu art. 33 que, antes do Processo Administrativo propriamente dito, poderá a autoridade competente abrir investigação preliminar, cabendo, para tanto, requisitar dos fornecedores informações sobre as questões investigadas, resguardado o segredo industrial, na forma do disposto no $\S 4^{\circ}$ do art. 55 do Código do Consumidor (FILOMENO, 2005, p. 152).

Um aspecto de atuação do PROCON diz respeito ao papel de elaboração, coordenação e execução da política local de defesa do consumidor, incluindo as atribuições de orientar, educar, coibir e restringir, dentre outras, a prática de abusos praticados no mercado de consumo, que possam causar prejuízos aos consumidores.

\section{Os casos: Toyota-Corolla e ponto-extra de TV a cabo}

\subsection{O caso Toyota-Corolla}

A Toyota, uma das maiores fabricantes de automóveis do mundo, presente em mais de 160 países e no Brasil, iniciou as suas atividades como montadora de veículos, em 1958 com a instalação da primeira fábrica brasileira em São Paulo. Até dezembro de 2004, a marca contava com 90 concessionárias, passando em 2008, com cobertura geográfica superando $90 \%$ do território brasileiro. Já possui 122 concessionárias espalhadas pelo país.

Após a verificação de que alguns automóveis do modelo Corolla apresentavam problemas de aceleração contínua (o que colocava em risco a vida de pessoas), o PROCON Estadual mediante decisão num processo administrativo proibiu a comercialização pela Toyota e seus concessionários do modelo em todo o território de Minas Gerais.

Foram relatados nove casos de veículos que apresentaram o defeito. Segundo o fabricante, o problema era causado pela falta de fixação do tapete que se deslocava e acelerava o automóvel. Segundo o Ministério Público-MG, essa informação não era dada ao consumidor no momento da compra, nem estava visível no interior do veículo. Constava apenas no manual de instruções do carro, o que não atendia a exigência do Código de Defesa do Consumidor.

A suspensão das vendas ocorreu após o depoimento no processo administrativo de três donos de automóveis Corolla que sofreram acidentes causados pelo travamento do pedal do acelerador, devido ao deslocamento do tapete. De acordo com o Ministério 
Público, a comercialização e venda do modelo só poderia ser liberada quando o fabricante adotasse medidas saneadoras do problema.

A montadora de automóveis e suas concessionárias, irresignadas com a decisão administrativa que proibia a venda de seus produtos, recorreu ao Poder Judiciário em busca de ordem para revogar as sanções administrativas que lhe vedavam o comércio.

No Mandado de Segurança impetrado, os autores alegaram que a penalidade imposta pelo PROCON e pelo Ministério Público feriu princípios constitucionais, como o princípio do contraditório, da livre iniciativa e da ampla defesa processual. Argumentou-se principalmente que não foi oportunizado para o grupo empresarial penalizado a possibilidade de apresentar defesa no procedimento administrativo que investigou o caso, antes de sofrer a punição administrativa.

$\mathrm{Na}$ instância monocrática, a decisão do writ foi denegatória. A Magistrada ${ }^{6}$ que julgou o Mandado de Segurança afirmou que Sistema Nacional de Defesa do Consumidor SNDC (Decreto Federal 2.181/1997), garante a aplicação de medidas cautelares - no caso, a suspensão da venda do Toyota-Corolla, quando as regras do CDC (Código de Defesa do Consumidor) não forem respeitadas e que o Ministério Público e o PROCON têm "competência para a instauração de Processo Administrativo bem como para a aplicação de penalidades", inclusive medidas cautelares, uma vez que integra o SNDC.

De acordo ainda com o Poder Judiciário a fabricante estava tendo um comportamento "omissivo" e não tomou nenhuma "medida efetiva e segura" para resolver o problema. Ao negar a liminar, observou-se também que a montadora não negava a existência do defeito.

Em síntese, a decisão administrativa cautelar suspendeu a comercialização e revenda dos veículos Toyota-Corolla no território mineiro. Assim, a empresa precisou tomar as medidas necessárias para garantir a utilização segura do veículo a fim de retornar às atividades no mercado com relação a este produto.

Apesar de posteriormente o Tribunal de Justiça de Minas Gerais ter deferido medida liminar para o reinício das vendas do veículo nos 12 (doze) distribuidores da marca no Estado, a Toyota teve que iniciar a maior série de recalls da indústria automobilística

\footnotetext{
6 Juíza Mariângela Meyer Pires Faleiro, titular da 7ạ. Vara da Fazenda Pública da Comarca de Belo Horizonte. 
mundial. Através de ajuste com o Grupo de Estudos Permanentes de Acidentes de Consumo (GEPAC) foi conduzido o recall de 107 mil unidades do modelo Corolla no Brasil.

\subsection{0 caso do ponto extra de TV a cabo}

Em face de diversas queixas formuladas por consumidores usuários do serviço de TV a cabo que discordavam da cobrança do chamado ponto extra ou ponto adicional, instaurou-se no ano de 2001, o Processo Administrativo no 509/01, em face da empresa Net Belo Horizonte Ltda., uma vez que configurava a prática do ilícito consumerista, previsto no art. 39, V do CDC e no art. 12, VI do Decreto 2.181/97, visto que a cobrança de ponto extra ou adicional em decorrência da inexistência de previsão legal para a cobrança, e por não constituir remuneração em contrapartida a serviço prestado, é prática infrativa de exigência abusiva.

A empresa Net, que oferece TV por assinatura, telefone fixo e internet de bandalarga, via cabo, com vendas de 3,5 bilhões de dólares em 2009, destacou-se por seus resultados financeiros, com crescimento de 27,3\% em relação a 2008. A empresa NetWay é uma empresa de telecomunicações, com foco em provimento de acesso a Internet com tecnologia via rádio para o mercado corporativo e residencial. Ela iniciou suas atividades no ano de 2007, na cidade de Arcos/MG.

O PROCON estadual e o Ministério Público sustentaram que ao final do procedimento administrativo, ficou comprovada a prática da conduta abusiva que motivou a autoridade a proferir decisão administrativa, que resultou na aplicação de sanção de multa no valor de $\mathrm{R} \$ 521.000,00$. A empresa recorreu, sem sucesso e a decisão administrativa transitou em julgado, entretanto a multa não foi paga, sendo o valor inscrito em dívida ativa, e a certidão remetida à Procuradoria do Estado para a cobrança judicial.

Em 20 de setembro de 2005, foram comprovadas as práticas de conduta abusiva, resultando em sanções administrativas consistentes em multas administrativas, no importe de $\mathrm{R} \$ 1.590 .406,74$, em face da Empresa NET, em razão de conduta reincidente e no valor de $\mathrm{R} \$ 729.640,09$, em desfavor da WAY TV.

Em 16 de março de 2010, o Tribunal de Justiça de Minas Gerais determinou às requeridas NET TV e WAY TV, condenadas solidariamente, ao pagamento de indenização por 
danos morais no importe de $\mathrm{R} \$ 500.000,00$, quantia esta a ser revertida ao Fundo Estadual de Proteção e Defesa do Consumidor.

As empresas requeridas foram condenadas na obrigação de não fazer, consistente em abster da cobrança do ponto extra ou adicional dos consumidores que estejam na área em que lhes foram outorgadas concessão para a exploração dos serviços de TV a cabo, seja na comarca de Belo Horizonte, seja em município de interior do Estado de Minas Gerais.

Determinou-se também que essas empresas continuem a ofertar o ponto extra ou ponto adicional aos consumidores/usuários que porventura solicitem, facultando a sua remuneração tão somente a título de adesão, cujo valor não deve ser superior a $50 \%$ do valor cobrado pela adesão, quando do início da prestação do serviço.

Em 16 de abril de 2009, a Anatel decidiu definitivamente pela proibição da cobrança do ponto extra da TV por assinatura. Segundo a Anatel, as operadoras só podem cobrar por eventos específicos como instalação ou o reparo de equipamentos "com problemas". No entanto, quem já possui um ponto extra não poderá ser cobrado retroativamente pela instalação dos aparelhos.

É interessante salientar que os dois casos analisados refletem as diferenças nas punições e questionamentos frente ao PROCON-MG, uma vez que no primeiro caso, diante da repercussão do fato que atingiu significativamente a sua imagem, a empresa Toyota acatou a decisão administrativa do PROCON-MG. Nesse sentido, um recall se fez necessário de 107 mil carros em todo o Brasil, a fim de corrigir as omissões que colocaram em risco a vida dos milhares de consumidores.

No que diz respeito ao segundo caso, continua uma polêmica, haja vista as inúmeras reclamações referentes à cobrança das despesas na instalação de equipamentos. É notório o desrespeito da Net Belo Horizonte e da Way TV Belo Horizonte, quanto ao abuso da prática do ilícito consumerista.

Portanto, observa-se que no segundo caso, referente às Empresas Net Belo Horizonte e da Way TV Belo Horizonte, a decisão administrativa punitiva não foi aceita pelas empresas operadoras de TV a cabo em Belo Horizonte. 


\section{Conclusão}

Este trabalho procurou apresentar um quadro dos problemas e dos êxitos oriundos da aplicação do Código de Defesa do Consumidor, fazendo uma análise do Direito Administrativo, do Processo Administrativo e dos órgãos públicos que participam da operacionalização dos direitos consumeristas, o PROCON e o Ministério Público Estadual.

Dois casos foram demonstrados para exemplificar, sendo que no primeiro (ToyotaCorolla), houve o acatamento da decisão administrativa, oriundo de Processo Administrativo instaurado para determinar a realização de recall em equipamento do veículo automotivo, no segundo caso (Ponto Extra de TV a Cabo), não houve o acatamento da decisão destinada a suspender a cobrança de ponto extra ou adicional de Televisão a Cabo.

Ressalta-se que não houve a pretensão de esgotar o assunto em termos definitivos, mas apenas demonstrar a situação atual de respeito aos direitos consumeristas, ao Código de Defesa do Consumidor e aos órgãos que fiscalizam sua aplicação, fazendo assim uma visão crítica dos aspectos mais relevantes do tema.

Com relação aos casos tratados, presume-se que no primeiro, da empresa Toyota, por se tratar de uma multinacional de renome internacional, e por disputar o mercado consumerista com outros produtores e montadoras de veículos, a abordagem da empresa se deu de maneira a acatar a decisão administrativa, minimizando os aspectos negativos que o problema poderia trazer para sua imagem e logo que a questão foi abordada com a empresa houve uma tomada de providências com vistas à solução do conflito instaurado, demonstrando no mínimo algum respeito com os direitos dos consumidores.

De forma contrária, ocorreu com relação ao caso do ponto extra ou adicional de TV a Cabo, com o conflito se arrastando desde 2001, revelando o desrespeito pelas normas consumeristas ao princípio da dignidade humana e da justiça contratual.

Conclui-se que a punição administrativa quase sempre é eficaz na proteção de defesa do consumidor. Contudo, o fornecedor de bens e serviços que não se resigna com as decisões e determinações dos Órgãos Públicos incumbidos de fiscalizar e aplicar a legislação de defesa do consumidor conseguem, toscamente, retardar ou impedir a aplicação destas decisões utilizando-se indiretamente do Poder Judiciário, através de ações e intermináveis recursos judiciais, para paralisar essas ações administrativas. 
Pode-se afirmar que, em decorrência das decisões proferidas pelo PROCON-MG, há um reflexo positivo que enseja em maior respeito na relação entre consumidor e fornecedor.

De acordo com a pesquisa, está evidente que o Código de Defesa do Consumidor motivou reações de vários segmentos da cadeia produtiva, o que proporciona benefícios para todos, podendo-se afirmar que o consumidor está mais consciente, mais exigente e mais ativo nas relações de consumo, uma vez que consegue resposta dos Órgãos de defesa do consumidor.

O foco deste trabalho não se restringiu ao estudo quantitativo, no sentido de afirmar o grau de eficiência dos Órgãos de Defesa do Consumidor em Minas Gerais, mas de confirmar que as ações administrativas de defesa do consumidor, aplicadas por estes entes, podem ser minimizadas na medida em que os fornecedores de bens e serviços se socorrem contra as sanções administrativas junto ao Poder Judiciário.

Objetivamente, confirma-se a hipótese de que os Órgãos de defesa do Consumidor têm uma força relativa, na medida em que, algumas medidas administrativas são acatadas imediatamente pelos infratores das leis de consumo, todavia a sociedade deve se mobilizar no sentido de buscar sanções mais densas contra os infratores destas leis para que se desestimule as práticas abusivas contra o consumidor.

Conclui-se, portanto, que, a proteção ao consumidor não se restringe à administração pública, sendo importante que a sociedade esteja ciente de seus direitos, se mobilize e permaneça mobilizada buscando aprimorar a qualidade sancionatória da legislação de defesa do consumidor, desestimulando os abusos do poder econômico e promovendo a justiça contratual, confirmando no Estado de Direito Brasileiro o paradigma constitucional do Estado Democrático de Direito.

\section{Referências}

ALMEIDA, P. S. de. Ambiente: direito de terceira geração e sua confirmação jurídica. Disponível em: <http://www2.oabsp.org.br/asp/esa/comunicacao/artigos/ambiente.pdf>. Acesso em: 02 nov. 2010.

ARIMA, K. NET é a empresa do ano. Disponível em: 
<http://info.abril.com.br/noticias/blogs/info/2010/08/09/net-e-a-empresa-do-ano/>. Acesso em: 15 out. 2010.

ASSIS, V.M. Almoêdo de. Estado, Igreja e Indígenas: administração portuguesa em uma condição colonial (A Problemática das Fontes). Disponível em:

<http:///apipucos.fundaj.gov.br/docs/indoc/cehib/almoedo.html>. Acesso em: 22 set. 2010.

BRASIL. CONSTITUIÇÃO (1988); OLIVEIRA, J. de (Org.). Constituição da República Federativa do Brasil: promulgada em 5 de outubro de 1988. 4. ed. São Paulo: Saraiva, 1990. viii. p. 168 (Legislação brasileira)

BRASIL. Lei n. 2181 de 20/03/1987. In: ANGHER, A. J. (Org.). Vade mecum acadêmico de direito. 8. ed. São Paulo: Rideel, 2009.

BRASIL. Lei n. 8078 de 11/09/1970. In: ANGHER, A. J. (Org.). Vade mecum acadêmico de direito. 8. ed. São Paulo: Rideel, 2009.

CARVALHO, D. P. A. de. O PROCON na defesa do consumidor. Revista Jurídica da Universidade de Franca, 2005.

CLARK, G. A proteção do consumidor e o direito econômico. Belo Horizonte: Interlivros Jurídica, 1994. p. 159[4].

CRUZ, C. R. da. Direito Administrativo Sancionador. Unidade I. Disponível em: <www.cead.unb.br/agu, Acesso em: 17 ago. 2009.

D' ANGELIS, W. As gerações de direitos humanos: terceira geração. Os direitos dos povos ou da solidariedade. Disponível em:

<http://www.dhnet.org.br/direitos/textos/geracaodh/gerac3.html>._Acesso em: 02 nov. 2010.

DI PIETRO, M. S. Z. Direito administrativo. 20. ed. São Paulo: Atlas, 2007. 800 p. . 500 anos de direito administrativo brasileiro. Revista Eletrônica de Direito do Estado, Salvador, 2002.

FARIA, E. F. de. Curso de direito administrativo positivo. 6. ed. rev. e ampl. Belo Horizonte: Del Rey, 2007. xxix, 774p.

FAORO, R. Os donos do Poder: formação do patronato político brasileiro. 4. ed.- São Paulo: Globo, 2008 
FILOMENO, J. G. B.; BENJAMIN, A. H. de V. e. A proteção ao consumidor e o Ministério Público. Justitia, 131 A, p. 73, set. 1985. 2005. 807 p.

. Manual de direitos do consumidor. 8. ed. rev., ampl., sist. e atual. São Paulo: Atlas, ,

FIUZA, C. Direito civil: curso completo. 13. ed. rev., atual. e ampl. Belo Horizonte: Del Rey, 2009.

GOMES, L.C. História da Administração: Evolução. Informativo Mensal do CRA, Ceará, v. 1, n. 7, ago./set. 2005.

HABERMAS, J. A inclusão do outro: Estudos de teoria política. São Paulo: Loyola, 2002

HISTÓRIA da Toyota do Brasil. Disponível

em:<http://www.toyota.com.br/sobre_toyota/brasil.asp>.Acesso em: 10 out. 2010.

HOFFE, O. O que é justiça? Porto Alegre: EDIPUCRS ,2003. (Coleção Filosofia, 155)

JUSTIÇA mantém proibição de venda do Toyota Corolla em Minas Gerais. Disponível em: http://ultimainstancia.uol.com.br/noticia/JUSTICA+MANTEM+PROIBICAO+DE+VENDA+DO+T OYOTA+COROLLA+EM+MINAS+GERAIS_69028.shtml/>. Acesso em: 09 out. 2010

MAGATÃO, K. da S. Tutela ressarcitória específica do consumidor. Revista de Direito do Consumidor, São Paulo, v.19, n. 75, p. 80-114, jul./set. 2010.

MARTIN, Henrique. Entenda a batalha pelo ponto extra da TV por assinatura. Disponível em: <http://tecnologia.uol.com.br/ultnot/2009/05/06/ult4213u737.jhtm>. Acesso em: 10 out.2010.

MELLO, Celso Antônio Bandeira de. Curso de direito administrativo. 21. ed. rev. e atual. até a Emenda Constitucional. São Paulo: Malheiros, p. 1040, 2006.

MINAS GERAIS. Ministério Público de Minas Gerais. PROCON estadual. Medida cautelar Toyota- Corolla. Disponível em: <http://www.mp.mg.gov.br/portal/public /noticia/index/id/1439> Acesso em: 06 out. 2010

MINAS GERAIS. Tribunal de Justiça de Minas Gerais. Processo no 061.487-2/06. Disponível em: <http://www.tjmg.jus.br/> Acesso em: 06 out. 2010

MINAS GERAIS. Constituição (1989). Constituição do Estado de Minas Gerais. 12. ed. Belo Horizonte: Assembléia Legislativa do Estado de Minas Gerais, 2005. 
NETWAY Telecom. Disponível em: <http://www.netway.psi.br/historia.html>. Acesso em: 15 out. 2010.

PONTIFÍCA UNIVERSIDADE CATÓLICA DE MINAS GERAIS. Pró-Reitoria de Graduação. Sistemas de Bibliotecas. Padrão PUC Minas de normalização: normas da ABNT para apresentação de trabalhos científicos, teses, dissertações e monografias. Belo Horizonte, 2008. Disponível em: <http://www.pucminas.br/biblioteca.> Acesso em: 05 nov.2010

SOUZA, M. de A. A política legislativa do consumidor no direito comparado. Belo Horizonte: Nova Alvorada, 1996. p. 244.

SARMENTO, D. A eficácia temporal das decisões no controle de constitucionalidade. In: CRUZ, Álvaro Ricardo de Souza (Coord.). Hermenêutica e jurisdição constitucional. Belo Horizonte: Del Rey, 2001.

SOUZA, W. P. A. de. Primeiras linhas de direito econômico. 6. ed. São Paulo: LTr, 2005. 603 p.

S. J. Luciano. Anatel: ponto extra na tv paga não é mais cobrado. Disponível em: <http://mesquita.blog.br/anatel-ponto-extra-na-tv-assinatura-paga-nao-e-mais-cobradodiario-oficial-mensalidade>. Acesso em: 10 out. 2010.

STOCKER, S. Mas sem perder a ternura: a história do movimento das donas de casa e consumidores em Minas Gerais. Belo Horizonte: jun. 2010.

TOYOTA Corolla volta a ser vendido em Minas Gerais. Ministério Público de Minas suspende vendas do Toyota Corolla no Estado. Disponível em: <http://www.estadao.com.br/estadaodehoje/20100422/not_imp541434,0.php>. Acesso em: 09 out. 2010.

TRIBUNAL de Justiça do estado concedeu liminar à Toyota do Brasil. Vendas haviam sido suspensas após decisão do Ministério Público de MG. Disponível em:

<http://g1.globo.com/carros/noticia/2010/05/toyota-corolla-volta-ser-vendido-em-minasgerais.html>. Acesso em: 10 out. 2010.

WEBER, Max. Os Fundamentos da Organização Burocrática: uma Construção do Tipo Ideal. In: CAMPOS, Edmundo. Sociologia da Burocracia. Rio de Janeiro: Zahar, 1976. 153 p. 
ReVista de Direito Público, LondRINA, V. 7, N. 1, P. 69-94, JAN./ABR. 2012. 